\title{
STANDARDS AND INFRASTRUCTURE FLEXIBILITY: LITERATURE REVIEW
}

\author{
Jaroslav Spirco, Vladislav Fomin and Tineke M. Egyedi \\ DELFT UNIVERSITY OF TECHNOLOGY
}

\begin{abstract}
Based on a literature review the paper investigates how standards influence flexibility of information technology (IT) infrastructures. Thereby we explore the concept of flexibility, the ways of achieving it and identify the characteristics of standards that influence flexibility. The existing literature regards standards both as a stabilizer of technology and as a means to increase flexibility. We conclude that both views are well supported and do not contradict each other, and both flexibility and stability are required for the development of infrastructures. Even though some characteristics of standards can directly influence infrastructure flexibility, the way standards are implemented will also determine their influence on flexibility. We exemplify the developed ideas with some examples from the radio frequency identification (RFID) technology in supply chain infrastructures.
\end{abstract}

\section{Introduction}

$\mathrm{I}$ n our daily life we heavily depend on technology. We don't realize the whole complexity of technological solutions and in many cases start noticing their existence only when things go wrong. The problems become particularly noticeable when technology infrastructures fail to provide the required level of services.

Whether it's small or large infrastructures, from time to time they have to adapt to meet an ever changing demand. A closed lane on a highway during the rush hour when additional lane is being built. An electricity power cut during the construction work in the neighborhood when new power installations are being made or the old power lines being replaced. The range of problems that adaptations of technology infrastructures can cause to its regular users is wide. So is the list of technology infrastructures, from physical transportation infrastructures like roads, railroads, electricity and water supply, to what became known as information infrastructures, like computer networks, mobile phone networks, payment systems, data exchange systems, to virtual infrastructures like supply chains, which exist only as routing schemes and business agreements, acquiring "materiality" only when transactions are made and ordered goods have to "travel" along the charted routes, accompanied by the flow of "zeroes" and "ones" of digital invoices in the realms of information infrastructures.

Apart from obvious technological challenges that infrastructure adaptation may face, there are issues pertaining to social aspects (e.g. Bijker, Hughes, \& Pinch, 1987; Hughes, 1983; Mayntz \& Hughes, 1988), economic aspects (e.g. Freeman, 1994; Shy, 2001), and managerial aspects (e.g. Tidd, Bessant, \& Pavitt, 1997; Utterback, 1994).

The change of infrastructures is complicated by such issues as high sunk cost of existing infrastructures, the large installed base of users (Farrell \& Saloner, 1986); the requirement of maintaining compatibility with the installed base when making changes; the learning required to use new infrastructural services (Star \& Ruhleder, 1996); the inter-dependence of different infrastructures (Edwards, 1998; Schneberger \& McLean, 2003).

Some infrastructures are more flexible than others, where flexibility is the ability of an infrastructure to adapt to meet the changing demand. The required level of flexibility depends on how quickly and to what extent the change of demand occurs. For instance in water supply infrastructures changes in demand occur at a much slower pace than in information technology (IT) infrastructures. According to this logic, IT infrastructures require a higher degree of flexibility, since the rate and extent of change of demand that IT infrastructures face is quite high. As IT infrastructures in their functioning rely more than any type of infrastructure on standards, the question arises whether standards can be used to facilitate change.

What makes infrastructures flexible? How can flexibility be achieved? Some approaches addressing the problems of infrastructure change focus on managing complexity (e.g. Newman, 2003), others on coping with social and institutional inertia (e.g. Hughes, 1983), or on the use of standards (e.g. Duncan, 1995; Egyedi, 2001; Egyedi \& 
Verwater-Lukszo, 2005; Fomin, 2003; Fomin \& Blechar, 2005; Hanseth, Monteiro, \& Hatling, 1996), still others focus on the modularity of systems (e.g. Schilling, 2000).

We look into existing literature to understand what makes infrastructures flexible and to what extent standards influence flexibility. First, we discuss practical motivation for the study and describe research methodology used. We then summarize the ideas present in literature. We illustrate our findings with the case of radio frequency identification (RFID) technology for supply chain infrastructures.

\section{Practical motivation for the study}

A modern infrastructure for supply chain management (SCM) is used for the exchange of data on the products and processes. Historically barcode technology was used to identify, trace and track items. This is also the area where the emerging radio frequency identification (RFID) technology can be applied. The barcode technology relies on a visual representation of identification information, while in RFID the identification information is stored on electronic tags and transmitted via radio waves. An SCM infrastructure based on barcode or RFID technology also includes a network that processes identification information coded in barcodes or embedded in electronic tags.

The recent advances in information and communication technologies have led to new requirements for the existing SCM infrastructures. For example many of the processes at all stages of production and distribution have become highly automated. In an automated environment tracking and tracing is particularly important as it provides visibility into business processes, helps identify bottlenecks and consequently leads to higher efficiency. Some limitations of barcode technology in an automated environment result from the requirement for direct visibility of a barcode to a reader, impossibility to uniquely identify items in bulk, and relatively low speed at which items can be scanned.

On the backdrop of barcode limitations, RFID technology emerged as a hopeful panacea ${ }^{1}$. In order to meet new requirements of the SCM an obvious solution would be to replace existing barcode-based infrastructure with a new infrastructure based on RFID. The early attempts to introduce the RFID technology in SCM infrastructures have largely failed, as the first generation ${ }^{2}$ of RFID could not provide the required level of flexibility in face of the change of demand.

A major problem with the adoption of RFID technology was the high cost of the already existing infrastructure based on barcode technology. Another important problem is in the realm of standards. Many existing RFID solutions are incompatible with each other, creating problems when incompatible solutions are integrated in one infrastructure. As a result, businesses that can potentially benefit from RFID technology are reluctant to invest in it for fear of their systems becoming incompatible with a new generation of RFID technology. ${ }^{3}$

Additionally the lack of frequencies at which RFID can operate around the world deters adoption of the technology. For example, North America uses $915 \mathrm{MHz}$ frequency while Europe employs $868 \mathrm{MHz}$ for Ultra High Frequency (UHF) RFID systems. In China, on the other hand, these frequencies are allocated for other applications. As a result the same RFID tags can not be used universally, further hindering flexibility of the RFID technology. This fact creates problems for the current value chain businesses which have become increasingly global in nature.

Unfortunately, the first generation of RFID standards could not successfully address these problems, which together with other factors of social and economic nature resulted in the low adoptions of RFID technology.

Can a new generation of RFID standards make SCM infrastructure based on RFID more flexible? To answer this question we need to understand how flexibility is achieved and how standards influence flexibility.

\section{Research methodology}

In order to provide answers to our research question we carried out literature review. For literature selection we adopted a three stage approach suggested by Webster and Watson (2002).

1. In order to identify major contributions to the field, we initially conducted a journal database search. For this purpose ProQuest database was queried with the keywords "flexibility" and "infrastructure". From the results we selected 10 articles most relevant to the topic which were published in the last 20 years in the field of technology management, economics and standardization.

2. After a quick analysis of the articles identified in step 1, we went "backward" by reviewing the citations in

\footnotetext{
${ }^{1}$ On the discussion on viability of RFID to solve all the problems see e.g. Lahiri (2006).

${ }^{2}$ Some differences between the first and the second generation of RFID standards are discussed later in the paper.

${ }^{3}$ Open standards can solve some of the incompatibility problems and support the adoption of new technology. Most barcode systems used nowadays are in fact based on open standards, which arguably benefited the wide adoption of barcode technology.
} 
these articles. As a result another 20 articles published prior were selected.

3. We then went "forward" using the Web of Science and Google Scholar citation index to identify articles citing the key articles selected during the previous two steps. ${ }^{4}$ In this step we selected an additional 30 articles.

As a result of all three stages we have identified a total of 60 articles. The content of all selected articles has been thoroughly analyzed. We then evaluated each article based on the extent to which the following issues were discussed:

1. The notion of flexibility (from various perspectives)

2. The role of standards

3. Technological aspects of infrastructure

4. Organizational aspects of infrastructure

5. Ways of achieving infrastructure flexibility from technological perspective

6. Ways of achieving infrastructure flexibility from organizational perspective.

For each article a score has been assigned in each category, from 1 (the least relevant) to 9 (the most relevant). The scores in categories 1, 2, 3 and 5 were given higher ratio than the ones in categories 4 and 6 . The sum of points accumulated by each article was then calculated and the top 30 articles were selected for the final analysis.

\section{Literature review}

Some limitations have become apparent during the literature review. Many studies don't discuss how to achieve flexibility and rather focus on the justification of flexibility. The focus is often on the organizational flexibility, which is seen as a result of human skills. At the same time technology flexibility is taken for granted. Additionally, some perspectives on flexibility do not form a coherent picture, with some contradictions on how to measure and achieve flexibility.

Being aware of these limitations we can start by discussing the concept of infrastructure and narrow it down to what makes infrastructures flexible and how standards can influence flexibility. Our discussion will focus on four areas:

1. Infrastructure flexibility.

2. Flexibility dimensions and measures.

3. Ways of achieving flexibility.

4. The role of standards.

\section{Infrastructure flexibility}

The definition of infrastructure depends on the field of application. In information system theories infrastructure is seen as a complex set of technological resources developed over time (e.g. Duncan, 1995). Most definitions of infrastructure differentiate two levels: basic technology components and resource planning (e.g. Bhatt \& Grover, 2005; e.g. Ciborra \& Hanseth, 1998; Duncan, 1995).

The change of infrastructures occurs at both levels. At the level of technology components infrastructures change is mainly accomplished by installing new components or changing the performance of existing ones. At the level of resource planning the development of technology components has to be aligned with the development strategy (Bhatt \& Grover, 2005; Duncan, 1995). The development strategy will to some extent determine at what parts of infrastructure flexibility is created. The required level of flexibility is determined by such factors as constant demand to reduce and control costs, rapid changes in technology, and customer expectations (Golden \& Powell, 2000; Nelson \& Ghods, 1998; Swafford, Ghosh, \& Murthy, 2006).

\section{The construct of flexibility}

The most commonly used definition of flexibility is "the ability to change or react with little penalty in time, effort, cost, or performance" (Upton, 1994, p. 73). Since the change of technology components of infrastructure is aligned with the development strategy, the definition of flexibility can be refined as "the ability to adapt to both incremental

\footnotetext{
${ }^{4}$ In some cases all three stages identified the same articles. This indicates that the chosen methodology for article selection yields a relatively complete census of relevant literature.
} 
and revolutionary changes in the business or business process with minimal penalty to current time, effort, cost or performance" (Nelson \& Ghods, 1998, p233).

The notion of minimal penalty is important. The idea of changing system's output without incurring extra expenses in terms of time and cost underlies all the definitions of flexibility in analyzed literature.

The relationship between time, cost and flexibility is a complex one. On the one hand literature suggests that the time and cost of flexibility are inversely related, as time taken for change may be shortened at extra cost, and the cost of making the change can be reduced by extending allowed time (Gupta \& Goyal, 1989; Slack, 1983). On the other hand, higher cost does not necessarily lead to higher flexibility. Flexibility cannot be bought; it must be planned and managed (Gupta \& Goyal, 1989; Gustavsson, 1984). It is possible to conclude that some flexibility can be achieved at an extra cost, but it is more important how flexibility is managed rather than how many resources are used.

How much flexibility does an infrastructure need? There appears to be a tradeoff between flexibility and stability. From the managerial standpoint stability is too valuable to be disregarded and flexibility if properly managed can potentially lead to efficiency. However, management of flexibility is difficult and therefore costly. The question is not simply how to achieve the highest level of flexibility, but how to achieve the right mix of stability and flexibility with minimal penalty (Adler, 1988; Harvey, Lefebvre, \& Lefebvre, 1997). The mix of stability and flexibility is reflected in the development strategy. If the development strategy presumes that the infrastructure will face a high level of demand change or if the uncertainty is high, the level of foreseen flexibility will normally be higher.

To understand flexibility it is helpful to identify its characteristics. For this purpose we compare the term flexibility with the synonymous terms adaptability, robustness, and agility.

While the term adaptability presupposes an ability of a permanent adjustment to a transformed environment, flexibility refers to only a temporal adjustment (Evans, 1991). Adaptability is also seen as an ability to change within a given state, while flexibility is a larger change which does not have to be specified in advance (Swafford, Ghosh, \& Murthy, 2006). We can therefore infer that flexibility is related to a change (a) of temporal nature (b) which can be both foreseen and unforeseen.

The term robustness refers to the ability to absorb the impact of unanticipated changes (Evans, 1991). Flexibility, in comparison with robustness presupposes the ability of change, rather than possessing excessive capacity. In principle by creating excessive capacity flexibility should also be increased. However, flexibility presupposes minimizing the cost of adaptation, while excessive capacity implies higher cost. Creating excessive capacity in infrastructure is often not a solution for flexibility. Flexible infrastructure has the ability to change, rather than the ability to absorb higher demand.

The third term commonly used in the same context as flexibility is agility, which is defined as an ability of being nimble to change (Evans, 1991). While the term agility focuses on the rapid response to the change in environment (Swafford, Ghosh, \& Murthy, 2006), for flexibility the ability to change in itself is more important.

The comparison of the terms yields the following characteristics of flexibility: (1) temporal change; (2) foreseen and unforeseen adaptation in the absence of excessive capacity; (3) ability to change when necessary.

The characteristics of flexibility help in understanding the concept, but do not explain how flexibility can be measured. In order to measure flexibility we next identify the flexibility dimension. The literature talks about the following flexibility dimensions relevant for our study ${ }^{5}$ :

1. Temporal, defined by how long it takes an infrastructure to change (adapted from Evans, 1991; Golden \& Powell, 2000). This dimension does not completely match the temporal characteristic of flexibility that we have identified, as the temporal characteristic refers to a temporal change, while temporal dimension refers to how quickly the infrastructure changes.

2. Range, defined by the scale of adjustment required for foreseen or unforeseen changes (adapted from Golden \& Powell, 2000). The notion of foreseen and unforeseen changes was also present in the characteristics of flexibility identified above.

3. Intention, which defines whether the infrastructure change is proactive or reactive (adapted from Evans, 1991; Golden \& Powell, 2000). The dimension of intention implies that the flexibility can be planned for and therefore can be used to achieve strategic advantage.

These flexibility dimensions can be measured in terms of time, range, variety of change or output as well as cost or effort required for change (Lee \& Xia, 2005; Swafford, Ghosh, \& Murthy, 2006).

\footnotetext{
${ }^{5}$ The literature also identifies the dimension of focus, which refers to the degree to which flexibility is internal or external to organization (Golden \& Powell, 2000). Because of the large scale of infrastructures, we believe that this dimension can not be applied to the infrastructures, but only to the information systems.
} 
The three flexibility dimensions found in literature only partially reflect the flexibility characteristics that we have identified. To avoid the confusion, we will base our analysis on the flexibility dimensions, while reserving the discussion of flexibility characteristics only for the purpose of explaining the concept of flexibility.

In relation to the levels of infrastructure identified in the previous section, the temporal dimension and dimension of range refer to the level of technical components, while the dimension of intention refers to the level of resource planning.

In what follows we relate the flexibility dimensions to the ways of achieving flexibility.

\section{Ways of achieving flexibility}

The reviewed literature reveals several ways of creating infrastructure flexibility. On the level of technology components the literature identifies two approaches: modularity and use of technology options. On the level of resource planning the approach of infrastructure decentralization summarizes several ways of managing infrastructure flexibility.

\section{Modularity}

The most well understood way of creating flexibility is through modularity of infrastructure components. High infrastructure flexibility implies a high degree of reusability and interchangeability among the infrastructure components (Egyedi \& Verwater-Lukszo, 2005; Kayworth, Chatterjee, \& Sambamurthy, 2001). Additionally, modularity reduces design complexity of infrastructure (Swafford, Ghosh, \& Murthy, 2006).

\section{Options}

There appears to be a lack of agreement in literature concerning the influence of technology options on flexibility. On the one hand some studies indicate that creating a range of option before they are needed is a way to achieve flexibility (Evans, 1991; Patten, Whitworth, Fjermestad, \& Mahinda, 2005). Flexibility in this case has some characteristics of robustness, when the resources are used to create excessive capacity.

On the other hand, the influence of options on flexibility is strongly determined by how these options are used. It appears that a high number of options can actually increase cost and decrease flexibility. Most of the value of flexibility can be obtained at low cost because only a few options are required. Additionally, a small number of options can be more valuable than the large number of options, as a small number of options may be more different from each other than a large number of options (Gerwin, 1993). For example, the use of a small number of predetermined sizes of freight container actually increases the flexibility of freight infrastructure. If a larger range of sizes were used, it would result in an unnecessary complex infrastructure and extra management costs.

\section{Decentralization}

On the level of resource planning, two solutions of infrastructure design are possible: decentralization and centralization (Allen \& Boynton, 1991). In the former, technology is dispersed throughout organization, in the latter technology is centralized. Decentralization creates speed and flexibility, while centralization permits large system restructuring and leads to efficiency and economy of scale. This suggests that when flexibility is required, decentralization is preferable. However, since in their management infrastructures always balance between efficiency and flexibility, a balance between centralized and dispersed infrastructure is beneficial. In this case the subsystems of infrastructure where stability is required can be centralized, and the subsystems that require flexibility can be decentralized.

Both modularity and the use of technology options can lead to less time required for infrastructure change, as well as the increased range of change, providing flexibility on the temporal and range dimensions identified above. By following centralized or decentralized design it is possible to change infrastructure offensively or defensively, providing flexibility on the dimension of intention. This idea is summarized in Table 1.

\begin{tabular}{|l|l|l|l|}
\hline $\begin{array}{l}\text { Flexibility } \\
\text { dimension }\end{array}$ & Temporal & Range & Intention \\
\hline $\begin{array}{l}\text { Ways of achieving } \\
\text { flexibility }\end{array}$ & options, modularity & options, modularity & Decentralization/centralization \\
\hline
\end{tabular}

Table 1. Ways of achieving flexibility

In what follows, we discuss how standards can influence flexibility by supporting the ways of achieving flexibility. 


\section{The relationship between standards and flexibility}

With the exception of several studies in our literature analysis (Allen \& Boynton, 1991; Bhatt, 2000; Ciborra \& Hanseth, 1998; Duncan, 1995; Egyedi, 2001; Egyedi \& Verwater-Lukszo, 2005; Hanseth, Monteiro, \& Hatling, 1996), the role of standards in flexibility is almost completely ignored.

The studies that deal with the topic of standards can be largely summarized by the following flexibility characteristics of standards (adapted from Egyedi \& Verwater-Lukszo, 2005): degree of specificity, degree of functional inclusiveness, and system level addressed by standards ${ }^{6}$.

Degree of specificity refers to the measures of detail in a standard, which is well seen when comparing product specifications with performance standards. Product specifications define the characteristics of technology, while performance standards specify how technology should function. Performance standards can potentially improve flexibility as they leave room for technology to manoeuvre to achieve a required result without specifying ways of achieving it. In application to the dimensions of flexibility discussed above, the degree of specificity influences both temporal and range dimensions of flexibility by providing specifications within which change can occur.

Degree of functional inclusiveness refers to the options that standards provide. Literature suggests that this characteristic is strongly determined by the factors of standard implementation (Egyedi \& Verwater-Lukszo, 2005). The characteristic of the degree of functional inclusiveness falls in both temporal and range dimensions. Options influence the change of infrastructure on the level of technology components.

System level addressed by standards refers to a level of infrastructure subsystems that standards address. Infrastructures consist of several subsystems. Depending on what subsystem a standard addresses, different levels of flexibility can be achieved. For example, communication standards support data exchange and provide the possibility to link the top software level of infrastructure. As such they make it possible to decentralize infrastructure subsystems and only link the top level of applications.

In relation to the ways of achieving flexibility that we have discussed above, we have identified some correspondence with flexibility characteristics (Table 2).

\begin{tabular}{|l|l|l|l|}
\hline $\begin{array}{l}\text { Flexibility } \\
\text { dimension }\end{array}$ & Temporal & Range & Intention \\
\hline $\begin{array}{l}\text { Ways of achieving } \\
\text { flexibility }\end{array}$ & options, modularity & options, modularity & decentralization \\
\hline $\begin{array}{l}\text { Flexibility } \\
\text { characteristics of } \\
\text { standards }\end{array}$ & $\begin{array}{l}\text { degree of specificity, } \\
\text { functional inclusiveness }\end{array}$ & $\begin{array}{l}\text { degree of specificity, } \\
\text { functional inclusiveness }\end{array}$ & system level \\
\hline
\end{tabular}

Table 2. Correspondence of flexibility characteristics of standards with flexibility types and ways of achieving flexibility.

Another idea identified in the literature is that paradoxically both flexible and inflexible standards can increase flexibility (Egyedi, 2001). For example, TCP/IP protocol that Internet is based on is rather inflexible. Because the level of simplicity of TCP/IP protocol is high, it provides flexibility to the whole system by making subsystems stable and allowing changes between them, e.g. changes in the content of messages, thus creating a form of modularity. In other words, by providing stability of the systems in some parts, standards leave room for change in other parts.

To explore the influence of standards we will next discuss the characteristics of standards in relation to the ways of achieving flexibility identified above (modularity, options, and decentralization):

\section{Modularity}

In a modular system, standards provide the possibility to mix different modules together. The main function of standards in this respect is to provide interconnection and support reusability of infrastructure parts and components. Some reusability objectives are: exchangeability, portability, scalability, extendibility or upgradeability, integration, interconnectivity, reversibility and downgradeability (Egyedi \& Verwater-Lukszo, 2005). Reusability of components supports modularity of the infrastructure, which consequently leads to flexibility.

\footnotetext{
${ }^{6}$ The fourth characteristic of "level of abstraction" is in our context similar to "the degree of specificity" and was therefore excluded from analysis.
} 
Options

Many changes in infrastructure are difficult if not impossible to predict. It is also impossible to specify from the outset all the necessary options in a standard. Specifying too many options makes standards difficult to implement and the resulting infrastructure becomes too complex and too costly to manage.

\section{Decentralization}

Depending on development strategy, some parts of infrastructure have to provide stability while other parts have to remain flexible. Standards can both support stability and flexibility. On the one hand, because infrastructures are large, their dispersed location and strong interdependence of its components require standardization, which can lead to the build up of resistance against further modifications (Hanseth, Monteiro, \& Hatling, 1996). On the other hand, when parts of an infrastructure are standardized, flexibility is created in other parts.

To achieve the necessary mix of stability and flexibility in an infrastructure, centralized approach can be adopted for the parts of infrastructure where stability is required, and dispersed approach can create flexibility in the respective parts. When it comes to decentralization standards support data exchange and ensure that the dispersed parts of infrastructure can interoperate (Bhatt, 2000).

Table 3 summarizes the findings of the literature review.

\begin{tabular}{|l|l|l|l|}
\hline $\begin{array}{l}\text { Flexibility } \\
\text { dimension }\end{array}$ & Temporal & Range & Intention \\
\hline $\begin{array}{l}\text { Ways of } \\
\text { achieving } \\
\text { flexibility }\end{array}$ & options, modularity & options, modularity & decentralization/centralization \\
\hline $\begin{array}{l}\text { Flexibility } \\
\text { characteristics of } \\
\text { standards }\end{array}$ & $\begin{array}{l}\text { degree of specificity, } \\
\text { functional } \\
\text { inclusiveness }\end{array}$ & $\begin{array}{l}\text { degree of specificity, } \\
\text { functional inclusiveness }\end{array}$ & system level \\
\hline $\begin{array}{l}\text { The role of } \\
\text { standards }\end{array}$ & $\begin{array}{l}\text { specification of only } \\
\text { necessary options; } \\
\text { Interconnection and } \\
\text { interoperability } \\
\text { (interface standards) }\end{array}$ & $\begin{array}{l}\text { specification of only } \\
\text { necessary options; } \\
\text { Interconnection and } \\
\text { interoperability } \\
\text { (interface standards) }\end{array}$ & $\begin{array}{l}\text { interoperability, data exchange } \\
\text { (mainly communication standards) }\end{array}$ \\
\hline
\end{tabular}

Table 3. The role of standards for infrastructure flexibility.

The relation between concepts is in reality more complex than illustrated. In some cases we have failed to identify a strict correspondence between the categories. For instance, all flexibility characteristics can in some cases address each dimension of flexibility, providing flexibility on the temporal, range, and intention dimensions. Additionally, as it appears in Table 3, the temporal and range flexibility dimensions are equally influenced by the standards. This can be partly explained by the fact that it is impossible to differentiate on the conceptual level if certain characteristics of standards influence the time or the range of infrastructure change, or both.

\section{Case application}

Literature analysis revealed the dimensions of flexibility, its measures and ways of achieving flexibility. It was also discussed how standards can influence flexibility by supporting modularity, providing only necessary options and enabling data exchange. We can now apply these findings to the case of RFID technology in supply chain management.

The problems with RFID adoption identified above are (a) lack of compatibility between existing RFID technological solutions, which at least partially is the result of (b) incompatibility of radio frequency bands allocated to the use of RFID in different regions, and (c) the high cost of already existing infrastructure.

The stand that we took at the beginning of the paper was that the first generation of RFID technology could not provide enough flexibility for the system to be successfully adopted. To prove this point it is necessary to briefly discuss the development of RFID standards.

The development of RFID standards have been largely shaped by two global organizations - EPCglobal and International Standards Organization (ISO). In 1990s Auto-ID center, which later developed into EPCglobal initiated the creation of a global standard for RFID. The specifications developed include Electronic Product Code (EPC) tag data specification, Class 0 RFID tag specifications and Class 1 RFID tag specifications. 
In application to the flexibility dimensions discussed above, the EPC Class 0 and Class 1 did not support flexibility on the range dimension, as they did not provide compatibility with other RFID solutions, with some difference in data format, communication protocols and radio frequencies used. The same compatibility issues made it difficult to decentralize the RFID systems, rendering them inflexible on the dimension of intention.

In 2004 EPCglobal approved new Class Gen2 RFID specifications. In comparison with the previous versions of RFID specifications, the new Gen2 provides better flexibility from several perspectives. It established a single UHF specification, which could be compatible with ISO 18000 specifications, developed earlier by ISO. As a result it addressed the problem of frequency availability that was hindering RFID deployment around the world. By providing compatibility with different tags, the Gen2 specifications improved range flexibility. On the level of functional inclusiveness Gen2 provides an option of adoption of some product extensions like higher function RFID tags, so it is expected to be compliant with Gen3 tag. Potentially, this option can increase flexibility if the higher function RFID tags are to be implemented in the future. On the other hand, if the option proves unnecessary, it can only make the implementation of Gen2 standard more difficult and the resulting infrastructure more complex. To a large extent the influence of this option on flexibility will depend on how the standard is implemented.

Another way that the Gen2 standard influences flexibility is by providing backward compatibility with the EPC Class 1 tags, which are still prevalent in deployment, meeting one of the reusability objectives and thereby supporting modularity.

In 2005 EPCglobal applied for ISO approval for its Gen2 standards. In July 2006 Gen2 standard was approved by ISO as an amendment to ISO 18000-6. Systems built based on ISO 18000-6 possess flexibility on the range dimension as they can interoperate with different tags, which could not be compatible earlier. The approval of EPCglobal Gen2 standard had some wide implications for the global adoption of RFID, easing the concern of international businesses about the compatibility of their systems with other RFID solutions.

Another problem, specific for SCM infrastructures, is the high cost of the existing infrastructure based on barcode. The existing infrastructure can be reused by gradually integrating RFID technology at some subsystems where the use of RFID has already been proven to bring benefits. Other subsystems can still continue to employ solutions based on barcode. In this case the dispersed arrangement of infrastructure can be supported by means of data integration from different technological solutions. For example, EPCglobal LLRP standard can be used to provide common extensible interface to middleware and different types of networking software. Another example is the use of open standards such as XML to establish interoperability on the level of applications and to avoid technology provider lock-in. In this case the subsystems will be dispersed, providing flexibility and data processing will be centralized, providing the necessary stability.

Whether the dispersed or centralized approach is adopted depends on the specific purpose the technology serves. Some degree of experimentation is always necessary. In the development of the Gen2 standard, previous experience with EPC Class0 and Class1 was taken in consideration. Additionally, even if Gen2/ISO 18000-6 standard can provide a higher degree of flexibility than the previous versions of the standard, the way they are implemented will to a large extent determine how flexible the infrastructure is.

\section{Conclusions}

In our study we aimed at understanding the concept of infrastructure flexibility and the role of standards it in. We started our analysis by discussing the concept of infrastructure, which consists of the level of technology components and the level of resource planning.

On the level of technology components of infrastructure we have identified the temporal and range dimension of flexibility, which turned out to be almost identical in the way they are influenced by standards. On the level of resource planning the change of technology components has to be aligned with development strategy, bringing the managerial aspects into the picture of technology change. On this level the flexibility dimension of intention reflects the change of infrastructure both of offensive and defensive nature.

Infrastructure flexibility can be achieved through modularity of technology, by providing necessary options while leaving other options open and by centralizing the parts of infrastructure that need stability while dispersing the parts where flexibility is required.

It turned out to be rather challenging to identify the influence of standards on flexibility. The existing studies that touch upon the topic of standards in relation to flexibility provide an interesting perspective. On the one hand, standards make technology stable. On the other hand, some characteristics of standards can increase flexibility. We concluded that these perspectives do not contradict each other. Moreover, from the managerial standpoint a balance between flexibility and stability is beneficial. 
Among the characteristics of standards that influence flexibility we have identified degree of specificity, functional inclusiveness and system level of standards. Each of these characteristics influences flexibility in a different way. Additionally, the influence of standards on flexibility can be impacted by the way the standards are implemented.

In application to the case of RFID technology for supply chain management infrastructure, we have analyzed the distinction between Gen 1 and Gen2 RFID standards. We concluded that Gen2/ISO 18000-6 standard provides more flexibility to the infrastructure based on RFID technology in comparison with Gen1 standards. The lack of flexibility in the previous generation of RFID technology can to some extent explain the low level of adoption of RFID technology in SCM infrastructures.

The main limitation of our study is that it is explorative in nature. We managed to discuss the construct of flexibility rather extensively. However, the functioning of standards in respect to flexibility may not be covered completely. Because of such factors as standard implementation or difference in management practices, the discussed influence of standards on flexibility may not be equal in all types of technology and infrastructures. Therefore we recommend further case studies into the influence of standards on infrastructure flexibility.

\section{References}

Adler, P. S. (1988). Managing Flexible Automation. California Management Review, 30(3), 34-56.

Allen, B. R., \& Boynton, A. C. (1991). Information Architecture: In Search of Efficient Flexibility. MIS Quarterly, 15(4), 435-445.

Bhatt, G. D. (2000). Exploring the relationship between information technology, infrastructure and business process re-engineering. Business Process Management Journal, 6(2), 139-163.

Bhatt, G. D., \& Grover, V. (2005). Types of information technology capabilities and their role in competitive advantage: An empirical study. Journal of Management Information Systems, 22(2), 253-277.

Bijker, W. E., Hughes, T. P., \& Pinch, T. J. (1987). The Social construction of technological systems : new directions in the sociology and history of technology. Cambridge, Mass.: MIT Press.

Ciborra, C. U., \& Hanseth, O. (1998). From Tool to Gestell: Agendas for Managing the Information Infrastructure. Information Technology \& People, 4, 305-327.

Duncan, N. B. (1995). Capturing Flexibility of Information Technology Infrastructure: a Study of Resource Characteristics and their Measure. Journal of Management Information Systems, 12(2), 37-57.

Edwards, P. N. (1998). Y 2 K: Millennial reflections on computers as infrastructure. History and technology, 15(12), 7-29.

Egyedi, T. M. (2001). Infrastructure Flexibility Created by Standardized Gateways: The Cases of XML and the ISO Container. Knowledge, Technology, and Policy, 14(3), 41-54.

Egyedi, T. M., \& Verwater-Lukszo, Z. (2005). Which standards' characteristics increase system flexibility? Comparing ICT and batch processing infrastructures. Technology in Society, 27(3), 347-362.

Evans, J. S. (1991). Strategic flexibility for high technology maneuvers: A conceptual framework. Journal of Management Studies, 28(1), 69-89.

Farrell, J., \& Saloner, G. (1986). Installed Base and Compatibility: Innovation, Product Preannouncements, and Predation. The American Economic Review, 76(5), 940-955.

Fomin, V. V. (2003). The role of standards in the information infrastructure development, revisited. In J. L. King \& K. Lyytinen (Eds.), Workshop on Standard Making: A Critical Research Frontier for Information Systems (pp. 302-313). Seattle, Wash.

Fomin, V. V., \& Blechar, J. (2005). An Analytic Model for the Prospective Exploration of Emerging Infrastructures. The 4th Conference on Standardization and Innovation in Information Technology, 2005 101-113.

Freeman, C. (1994). The Economics of Technical Change: a Critical Survey Article. Cambridge Journal of Economics, 18(5), 463-514.

Gerwin, D. (1993). Manufacturing flexibility. A strategic perspective. Management Science, 39(4), 395-410.

Golden, W., \& Powell, P. (2000). Towards a definition of flexibility: In search of the holy grail? Omega, 28(4), 373-384.

Gupta, Y. P., \& Goyal, S. (1989). Flexibility of manufacturing systems. Concepts and measurements. European Journal of Operational Research, 43(2), 119-135.

Gustavsson, S.-O. (1984). FLEXIBILITY AND PRODUCTIVITY IN COMPLEX PRODUCTION PROCESSES. International Journal of Production Research, 22(5), 801-808. 
Hanseth, O., Monteiro, E., \& Hatling, M. (1996). Developing information infrastructure: The tension between standardization and flexibility. Science Technology and Human Values, 21(4), 407-426.

Harvey, J., Lefebvre, L. A., \& Lefebvre, E. (1997). Flexibility and technology in services: A conceptual model. International Journal of Operations and Production Management, 17(1), 29-45.

Hughes, T. P. (1983). Networks of power : electrification in Western society, 1880-1930. Baltimore: Johns Hopkins University Press.

Kayworth, T. R., Chatterjee, D., \& Sambamurthy, V. (2001). Theoretical Justification for IT Infrastructure Investments. Information Resources Management Journal, 14(3), 5-14.

Lahiri, S. (2006). RFID sourcebook. Upper Saddle River, NJ: IBM Press.

Lee, G., \& Xia, W. (2005). The ability of information systems development project teams to respond to business and technology changes: A study of flexibility measures. European Journal of Information Systems, 14(1), $75-92$.

Mayntz, R., \& Hughes, T. P. (Eds.). (1988). The Development of large technical systems. Frankfurt am Main: Campus Verlag.

Nelson, K. M., \& Ghods, M. (1998). Measuring technology flexibility. European Journal of Information Systems, 7(4), 232-240.

Newman, M. E. J. (2003). The structure and function of complex networks. SIAM Review, 45(2), 167-256.

Patten, K., Whitworth, B., Fjermestad, J., \& Mahinda, E. (2005). Leading IT Flexibility: Anticipation, Agility and Adaptability. Americas Conference on Information Systems, 11-14.

Schilling, M. A. (2000). Towards a General Modular Systems Theory and its Application to Interfirm Product Modularity. Academy of Management, 25(2), 312-334.

Schneberger, S. L., \& McLean, E. R. (2003). The complexity cross: implications for practice. Communications of the ACM, 46(9), 216-225.

Shy, O. (2001). The economics of network industries. Cambridge, U.K. New York: Cambridge University Press.

Slack, N. (1983). Flexibility as a manufacturing objective. International Journal of Operations and Production Management, 3(3), 4-13.

Star, S. L., \& Ruhleder, K. (1996). Steps Toward an Ecology of Infrastructure: Design and Access for Large Information Spaces. Information Systems Research, 7(1), 111-134.

Swafford, P. M., Ghosh, S., \& Murthy, N. N. (2006). A framework for assessing value chain agility. International Journal of Operations and Production Management, 26(2), 118-140.

Tidd, J., Bessant, J. R., \& Pavitt, K. (1997). Managing innovation: integrating technological, market, and organizational change. Chichester, West Sussex, England ; New York: Wiley.

Upton, D. M. (1994). The Management of Manufacturing Flexibility. California Management Review, 36(2), $72-89$.

Utterback, J. M. (1994). Mastering the dynamics of innovation: how companies can seize opportunities in the face of technological change. Boston, Mass.: Harvard Business School Press.

Webster, J., \& Watson, R. T. (2002). Analyzing the Past to Prepare for the Future: Writing a Literature Review. MIS Quarterly, 26(2), 13-23. 